\title{
Problem of Criteria Space Dynamism at Management and Conceptual Approaches for Its Solutions
}

\author{
Submitted 18/12/20, $1^{\text {st }}$ revision 28/01/21, $2^{\text {nd }}$ revision 19/02/21, accepted 20/03/21
}

\begin{abstract}
:
Purpose: The problem of criteria space dynamism at the management activity in terms of changing the composition of its dimensions in a finite number of moments is highlighted. For the management period, a non-element tuple of criterion spaces is introduced, which does not fit into the management theory's classical constructions. A typical example of the situation is declared for example as anti-crisis management. It is shown that the problem of criterion dynamics is significant in predictive analysis of the state and institutional and organizational in economics and electroanalytical studies. Accordingly, there were intentions to establish the necessity of the problem of the criterion space dynamism, identify the problems generated by this phenomenon, and propose a fan of methods for mapping an inhomogeneous criterion space into a homogeneous space.
\end{abstract}

Dmitriev Oleg Nikolaevich ${ }^{1}$

Design/Methodology/Approach: As a methodology, a complex of theories, scientific directions, and methods was used, among which system analysis, general control theory, optimization theory, and some others are distinguished.

Findings: The author argues for the relevance of reproducing the situation with the management of organizational and economic separations, in which the criterion space is dimensionally and subjectively dynamic. The inapplicability of traditional approaches to managing complex economic objects in the conditions of criterion dynamism is established. A set of methods is proposed that allow at least to smooth out the severity of the problem and introduce the projection of an inhomogeneous criterion space into a conditionally homogeneous criterion space.

Practical Implications: The proposed approach makes it possible to carry out an acceptably correct control in the conditions of changing a set of optimization criteria - both structural (dimensional) and characteristic (according to the evaluation procedure).

Originality/Value: The proposed methodological approach makes it possible to apply the central part of the accumulated management tools to manage conditions in a dynamic criteria space and thereby avoid catastrophic management errors, including in the conditions of changing management paradigms "crisis - non-crisis."

Keywords: Criterion coupling, criterion dynamics, criterion space, institutional and organizational separations, optimization.

JEL classification: C44, C61, D21, D81, L21.

Paper Type: Research Paper.

${ }^{1}$ Ph.D. of technics (engineering), full-doctor of economics, professor of management, professor of Department "Production management and marketing concerning high-tech industries", Moscow Aviation Institute, National Research University - MAI. Russia, olegdmitriev@yandex.ru 


\section{Introduction}

A characteristic feature of modern management of complex institutional organizational and eco-nomic objects is a high level of dynamism of their operation's external and internal environments and non-determinism of these dynamics. This complex phenomenon has been characteristic for a historically long period only for the so-called transition and developing economies. Recently, however, a high level of dynamism and unpredictability, including indignation, has been demonstrated by the economies of even the most economically developed countries at the macro levels, meso levels, and micro levels.

This situation, of course, is not entirely new in economic management. Crises, including global, country, and sectoral ones, have been observed more than once in recent world history. However, if situations with a global paralysis of economic life did arise, it was during the last world war, and even then, preferably locally, in capitulating countries.

The factors that disturb the management situations are the abrupt transformations of the pools of suppliers and customers of commercial products, conflict situations of the military, financial and economic, sanctions and other types of origin, and largescale natural disasters which epidemiological catastrophes suddenly became a priority.

Almost all persons who are involved in legal relations have an interest in obtaining useful management tools for new conditions (individuals are not discussed in this case, because their managerial problems, according to the author, go beyond the scope of the discussed problem), among which are highlighted:

- directorates and subdivisional administrations of all hierarchical levels of legal entities, enterprises;

- members of legal entities;

- $\quad$ specialized bodies of state and various regional administrations.

It is quite possible that this circle also includes other critically important persons, for example, from supranational administrative formations such as European Community and Eurasian Economic Union.

A fundamental feature of the current situation is that, along with the rather traditional factor dynamics of production and economic activity, there was generated objectively and inevitably at first the target dynamics of management staff: subjects of management, after it there was generated the dynamics of the composition of indexes of the financial and economic state of separations, and then there was generated the dimensional criteria dynamics. That is, it objectively arose the dynamics of criterial space (we should not confuse it with dynamic trajectories in dimensionally static criterial space). We single out the dynamics of the criterial space and not the dynamic criterial projection of the managed object into the dimensionally invariable criteria space. 
The accumulated theoretical knowledge and experience in applied management were mostly not applied to such situations. This thesis is revealed below in the framework of assessing the applicability of the accumulated "baggage" of the forerunners. Thus, there are objective grounds to admit that in current conditions, research in the development of constructions of the general theory of management, system analysis and optimization theory for the case when there is, or it is supposed to be the dimensional dynamics of the management criteria space are very relevant and practically valuable.

These studies closely correlate with the studies in scenario forecasting, in which scenarios are discriminated not only by the levels of favored/unfavorable factors but also by the behavioral models of influencing subjects. Various analytical research types are currently being conducted about various institutional, organizational, and economic separations.

Functional structuring of the managing system has long been established (Dmitriev, 2002a), although, unfortunately, there are still publications on the so-called General management with some non-scientific functional structuring. Accordingly, from two to five functional blocks are allocated. Formal-ly, they do not always include an analysis block. However, analytical functions are implemented in all five blocks. In the general case, we can distinguish two types of analytical studies: prognostic and retrospective ones. However, regardless of the type of period, any analysis is made based on the management's goal orientation. Therefore, there can be no analytical studies that are invariant concerning the criterion space. The utility of object states (referring to the well-known utility theory) is always projected into the criterion space. Accordingly, any statements, conclusions, and recommendations are "parameterized" by the criterion space in which the object of research is analytically placed.

\section{Theoretical Basis}

The following things were used as a theoretical basis for the author's research:

- general management theory;

- system analysis;

- organization theory;

- jurisprudence in terms of civil law;

- optimization theory;

- probability theory;

- theory of uncertainties;

- stability theory;

- information theory;

- experiment planning (design) theory;

- set theory and some other scientific theories related to operations research. 


\section{Methodology}

The general structuring of the research methodology is sufficiently fully covered, in particular, in the few works (for example, Bazadze, 2002; Vartanyan, 2008; Danilochkin, 2010; Danilochkina, 2001; Demchenko, 2011; Dmitriev et al., 2013; Dubovik, 2011; Ekshembiev, 2003); Ivanov, 2003, Cherner, 2019).

The author's development is conceptual and methodological and mainly concerns that part of the information and advisory system's systematic tools for supporting management decisions, which is associated with the synthesis of optimization criteria for these management decisions (Dmitriev, 2002). In this sense, methodologically, it relied on the construction of such a direction in the field of operations research as the so-called criterial synthesis or criterial design of managing systems. This direction is sometimes correlated with the synergistic superposition of utility theory in different interpretations (Shoemaker, 1982; General theory of utility, 2019) and linear algebra (Gelfand, 1998; Kleiner, 2007), as components of the emerging general and particular theories of spaces (of course, we are not talking about philosophical or physical ones, but only about mathematical aspects and constructions).

\section{Forerunners and Applicability of their Scientific Results}

The problem of managing complex objects, including institutional and organizational objects as economic objects and at the same time subjects, has been developing for a long time successfully in general. The fundamental foundations of the general theory of management applied to organizational and economic objects, laid down for a long time, are well known (Wiener, 1983; Forrestor, 1971). However, they conceptually did consider neither criterial variability nor dimensional criterial dynamics.

The closest in the profile are, undoubtedly, works related to the so-called adaptive systems. However, as it may not seem surprising, publications on this topic are quite limited in several just over 100 in all research areas. So, in the Unified Electronic Catalog of the Russian State Library (observed on November 22, 2020), several works can be attributed to profile materials (Grigoriev, 2012; Pyrkin, 2015; Ruban, 2018). Many of these publications are related to the so-called mechatronics, and almost everything is related exclusively to technology. Obviously, in robotics, the dynamism of optimization criteria is theoretically possible (for example, processing quality and processing speed), but combining these criteria within one technological task framework is more unusual. It was not possible to single out works in adaptive management about institutional and organizational systems.

The situation abroad is more positive. There, publications on similar topics are found (Bennet and Bennet, 2004; Solvit, 2012). However, firstly, they practically do not directly affect the management of institutional and organizational separations and, secondly, they do not relate to dimensional criteria dynamics. 
There are several publications about the field of anti-crisis management, but most of them are associated with the problem of short-term repayment of signs of the bankruptcy of enterprises: repayment of overdue accounts payable (Plaksin, 2007). Nevertheless, a few exceptions were identified: publications in which the problem of anti-crisis and sustainable management is posed more profoundly and correctly (Bloshenko, 2009; Zolotova, 2017). Nevertheless, in these works, the criterion space is considered unchanged for the entire period of management.

Thus, we have to state that the problem of adaptive management of institutional and organizational segregations in the context of the dynamism of the criterion space has not yet received an exhaustive study and disclosure, but has not even stood out in any significant way and has not been positioned as a critically important direction of the systems engineering design of control systems.

\section{Results and Discussion}

\subsection{Formalized Description of the Problem of Criteria Space Dynamism}

According to the general canons, we consider a certain system-technical dyad in the form of an abstract managed object and managing subject (Dmitriev, 2002). We will proceed from the assumption that the managed object is some complex object. In the future, when considering the abstract methods of solving the problem, the object will be substantively localized and considered institutional and organizational separation. For example, it can be all enterprises in the country, a corporate grouping of enterprises (industry, regional, holding, etc.), enterprise, or some of its subdivisions of one or another hierarchical level. That is, an object can be macroeconomic, macroeconomic, or microeconomic (Simakhin, 2019).

Naturally, the subject of management has and seeks to achieve specific goals about the object of management. We will proceed from the fact that these goals are quantitative because they organize and carry out management even in the absence of dimensional criteria dynamics (So-rokin, 2019).

In full accordance with the classical technology of systems engineering, the first indexes of the managed object's state are introduced, and after them, the optimization criteria are introduced. Whether the condition indexes and the optimization criteria are identical is irrelevant in this case. We consider a certain management period bounded on the left and right.:

$$
t \in\left(t_{\text {beg. }}, t_{\text {end. }}\right]
$$

where $\boldsymbol{t}_{\text {beg. }}$ is the beginning of the management period and $\boldsymbol{t}_{\boldsymbol{e n d}}$ is its end. 
This management period is divided into $N$ management sub-periods of the following form:

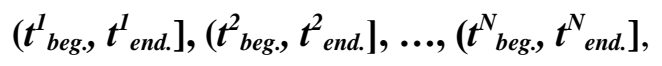

where the notation "beg." and "end." retain their semantic content, and the following relations are fulfilled:

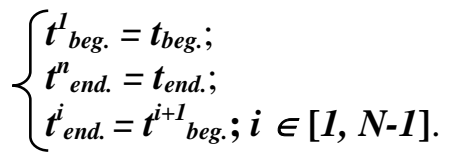

These sub-periods of management can have an arbitrary finite length and are docked close to each other (there are no sub-periods of management with unknown optimization criteria, because in this case, according to the foundations of scientific knowledge, management disappears as a category).

Accordingly, a time tuple of vector criteria for optimizing managerial decisions of the form is allocated:

$$
\begin{aligned}
& \left\{\vec{K}^{j}\left(t^{\langle j\rangle}, t^{j}{ }_{\text {beg. }}, t^{j}{ }_{\text {end., }}, t_{\text {beg. }}, t_{\text {end. }}\right)\right. \text {; } \\
& \left.j \in[1, N] ; t^{\langle j\rangle} \in\left(t^{j}{ }_{\text {beg. }}, t^{j}{ }_{\text {end }}\right]\right\}^{\prime} \text {, }
\end{aligned}
$$

where $\vec{K}^{j}\left(\boldsymbol{t}^{j\rangle}, \boldsymbol{t}_{\text {beg. }}^{j}, \boldsymbol{t}_{\text {end. }}^{j} \boldsymbol{t}_{\text {beg. }}, \boldsymbol{t}_{\text {end. }}\right)$ is the vector criterion for optimization of managerial decisions for $\boldsymbol{j}$-th management sub-period; $\boldsymbol{t}^{\langle j\rangle}$ is the calendar time for $\boldsymbol{j}$ th management sub-period, synchronous with the time $t$ for this sub-period, during which $\boldsymbol{j}$-th optimization criterion is applied (sub-period, during which this optimization criterion is relevant).

In this case, an introduction to the presentation of the optimization criterion for the parameters $\boldsymbol{t}_{\boldsymbol{b e g}}$. and $\boldsymbol{t}_{\boldsymbol{e n d} \text {. }}$ means that the optimization criterion is "valid", is applied to the management subperiod $\left(\boldsymbol{t}_{\text {beg.. }} \boldsymbol{t}_{\text {end. }}\right.$, , but can also be extended to the management period $\left(\boldsymbol{t}_{\text {beg. }}, \boldsymbol{t}_{\text {end. }}\right]$ or, more naturally and therefore most often, to the management period $\left(\boldsymbol{t}_{\text {beg. }}, \boldsymbol{t}_{\text {end. }}\right]$. In the economic sphere, there are situations when the retrospective is taken into account in full (for example, in a certain year there may be a focus on reimbursing the losses of the participants of a legal entity in terms of their income from participation in the enterprise for some past periods: a kind of compensatory dividends for the case of a joint-stock company). However, these interests and intentions should be reflected in the optimization criteria. Therefore, in the general case, for $j$-th optimization criterion, one should focus on the control period in the form $\left(\boldsymbol{t}_{\text {beg. }} \boldsymbol{t}_{\text {end. }] \text {. }}\right.$

However, the optimization criteria that relate to the already passed management subperiods should not be taken into account, respectively, because it is physically impossible to change their values. Therefore, the moment of time $\boldsymbol{t}_{\text {beg. }}$. can legitimately 
be considered the absolute beginning of the management period and not take into account the criterion retrospective, which may have taken place before this moment. Naturally, in the general case, the optimization criterion $\vec{K}^{p}\left(t^{\langle p\rangle}, t^{p}{ }_{\text {beg. }}, t^{p}{ }_{\text {end., }} \boldsymbol{t}_{\text {beg. }}, \boldsymbol{t}_{\text {end. }}\right)$ is not meaningfully identical to the optimization criterion $\vec{K}^{q}\left(t^{\langle q\rangle}, t^{q}{ }_{\text {beg. }}, t^{q}{ }_{\text {end., }}, t_{\text {beg. }}, \boldsymbol{t}_{\text {end. }}\right)$ for any different $p$ and $\boldsymbol{q}$, when $p, q \in[\mathbf{1}, \boldsymbol{N}]$. However, this does not exclude meaningful repetitions: for example, in relation to enterprise - commercial organization: "stereotypical functioning $\rightarrow$ crisis functioning $\rightarrow$ stereotypical functioning".

Obviously, within $\boldsymbol{t}^{\langle j\rangle} \in\left(\boldsymbol{t}_{\text {beg. }}^{j}, \boldsymbol{t}_{\text {end }}\right]$, the time for $\boldsymbol{j}$-th optimization criterion can have an arbitrary discreteness of its own. In this case, this discrepancy does not affect the constructions. Of course, in practice, most often for all optimization criteria, the same and uniform management discreteness is considered. We will assume that this discreteness is optimized in some way and is given a priori (Dmitriev and Novikov, 2019).

We try to simplify the task somewhat, judging from reasons of common sense that it initially looks too complicated. Undoubtedly, at the stage of the initial system engineering design, for each management sub-period, the problem of scalarization of $j$-th vector optimization criterion was solved. Such scalarization methods have been known for a long time and are widely used in theory and practice (Stadler, 1988; Dmitriev, 2002; Yu-Chi, Qian-Chuan, and Qing-Shan, 2007; Gorokhovik, 2012; Dmitriev et al., 2013). As a result, the problem under consideration is greatly simplified, and the tuple of optimization criteria takes on a scalarized form for each management sub-period:

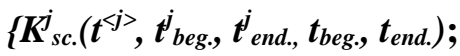

$$
\begin{aligned}
& \left.j \in[1, N] ; t^{\langle j\rangle} \in\left(t_{\text {beg. }}^{j_{\text {en }}} \boldsymbol{t}_{\text {end. }}^{j}\right]\right\} \text {, }
\end{aligned}
$$

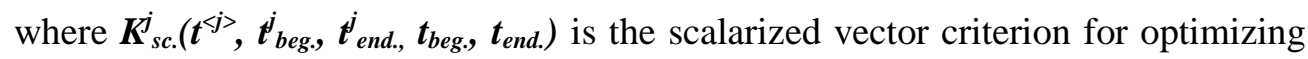
managerial decisions for $\boldsymbol{j}$-th management sub-period.

Thus, in dimensional criterial dynamics, a relatively well-known problematic task of vector optimization arises formally. However, it turns out to be quite specific and has not been considered in studies on optimization criteria' scalarization. Vectorial is associated with:

- state of the managed object is sequentially projected into dimensionally different criterion spaces;

- consequences of management concerning one component of a vector criterion generally entail delayed consequences for other components of a vector criterion in a potentially conflicting nature.

A manifested problem area is the imposition of anti-crisis management (including risk management) on dimensional criteria dynamics. In this case, the moments of the dimensional transformation of the criterion space may turn out to be random or even 
uncertain. That is, in this case, the management sub-periods turn out to have nondeterministic division boundaries (delimitations):

$$
\left(t_{\text {beg. }}^{1}, T_{\text {end. }}^{1}\right], \ldots,\left(T^{N}{ }_{b e g .}, t^{N} \text { end. }\right]
$$

where the capital letter $\boldsymbol{T}$ means the indeterminacy of the corresponding moment in time.

These non-deterministic time boundaries are subject to determination, and, accordingly, the tuple should be reduced to positioning in time in the following form:

$$
\left(t_{\text {beg. }}^{1}, \operatorname{Det}\left\{T^{1}{ }_{\text {end. }}\right\}\right], \ldots,\left(\operatorname{Det}\left\{T^{N}{ }_{\text {beg. }}\right\}, t^{N}{ }_{\text {end. }}\right]
$$

where Det is the operator of determination of a stochastic or uncertainty value (Shiryaev, 2020; Tilahun and Ngnotchouye, 2018). However, this issue seems to go too far beyond the mainstream of the discussed problems and therefore is further excluded from the discussion. Further, it is considered that the moments of transformation of the criterial space are deterministic and priori given.

\subsection{Practical Situations that Generate Dimensional Criterion Dynamics in the Field of Economics}

The emergence of dimensional criteria dynamics is entirely possible and is realized in practice in a relatively large number of cases. The relevant situations include the following:

- loss or threat of loss of a legal entity's financial and economic viability or a group of such persons. About their divisions, we are talking about pseudo bankruptcy (conditional bankruptcy);

- loss of sales markets or breakdown of cooperation ties, i.e., unilateral or bilateral loss of counterparty ties. This situation can arise for various reasons, including as a result of the initiation of sanctioning disadvantages;

- changes in the macroeconomic situation associated with natural disasters or involvement in a military conflict;

- changes in legislation, transforming the goal-setting of the implementation of production and economic activities;

- changes in the views of participants in enterprises (in terms of enterprises), directorates, and administrations (in terms of divisions of enterprises).

Proposed conceptual approaches to solving the problem of dimensional criteria dynamics

If the problem of dimensional criteria dynamics, interpreted above as a specific problem of vector optimization, objectively exists and has frequent practical manifestations, there are three fundamental options for attitudes towards it: 
- ignoring;

- artificial introduction of some fundamentally new scalar optimization criterion, replacing the prior existing vector optimization criterion, which became such due to dimensional criterion dynamics. However, as it is well known, the solution of the vector optimization problem is generally unattainable;

- solution of the problem or, at least, its mitigation or approximation to the solution due to the introduction of some innovative conceptual constructions.

The first of these methods, undoubtedly, is not resource-intensive; however, firstly, ignoring the problem does not solve it, and, accordingly, management becomes impracticable.

The second indicated method is, firstly, an attempt to solve the problem in the conditions of the lack of proof of its fundamental solvability and the absence of practical examples of solution (Nogin, 2005; Nogin, 2016) and, secondly, will undoubtedly lead to an undefined distortion of goal-setting for all sub-periods of management. The third indicated method seems suitable for trying to use it.

We consider the applicability of well-known conceptual approaches from other areas, their transformations, and innovations. Conceptual approach one is based on the socalled start-stop management, known, in particular, initially from the field of programming theory. Originally, it provided for tracing program execution (Zeller, 2006; Zeller, 2011). The meaning of this approach was the execution of an interactive program (analog of management) divided into several stages, at each of which the state indexes were estimated, and the final conditions were formed from the initial conditions, which, in turn, became the initial ones for the next period of the model time. This approach was used, among other things, within the framework of the author's research in the field of modeling the state of parks of equipment for the socalled suspended computer experiments (literally the so-called pause-points experiments: experiments with pause points), the duration of which went beyond the permissible boundaries of one session and therefore they were transformed into fragmented experiments. These points were provided for repeated simulation experiments and after a certain number of model events.

In the situation under consideration, such a start-stop was like a purely technical procedure and, in particular, made it possible to increase the probability of failurefree completion of a computational experiment and its resource intensity. In a particular case, the program provided for a periodic backup reset of the user DUMP file of the executable program, which allows, in the event of a failure of the computing environment, to conduct a computational experiment not from the starting point but the point of model time corresponding to the reset of this DUMP file.

In the situation under consideration, the management concerning the object from the side of the managing subject is segmented according to the selected management subperiods. At each $\boldsymbol{j}$-th of them, management is carried out sequentially in accordance 
with the initially introduced criterion for the optimization of managerial decisions $\boldsymbol{K}_{\text {sc. }}^{j_{c}}\left(\boldsymbol{t}^{\langle j\rangle}, \boldsymbol{t}_{\text {beg. }}^{j_{\text {e }}} \boldsymbol{t}_{\text {end., }}^{j} \boldsymbol{t}_{\text {beg. }}, \boldsymbol{t}_{\text {end. }}\right)$. Thus, the problem seems to be formally solved. However, in reality this is not at all case. It has been rigorously proven (Lasdon, 1975; Lasdon, 2002) this decomposition generally does not generate global optimality. Any decomposition with subsequent optimization for the components does not lead to finding the optimum for the whole decomposed object.

This conceptual approach is widely used in practice and represents the fateful orientation of management staff, ready to recognize the prospect of a crisis scenario, but giving absolute priority to overcoming the crisis.

It should be noted that there have been quite successful attempts to apply it to substantiate decisions to prevent crises and overcome them (Lapenkov, 2001; Bloshenko, 2009; Badalova and Minaev, 2016). However, this approach was correct only under the conditions of the realizability of the so-called "bounce" or Vdynamics, i.e. in fact, in the restoration of the pre-crisis management situation. Conceptual approach two is based on introducing additional pseudo-subject management superstructure based on the so-called arbitration management (Dmitriev, 2011).

Within the framework of the considered problems, it looks like this:

- management system is conventionally cloned for each of $\mathrm{N}$ selected management sub-periods, and thus $\mathrm{N}$ managing systems arise, for each of which there is a corresponding optimization criterion. These managing systems are interpreted as managing systems of the lowest hierarchical level;

- new non-subject managing system is introduced, for which cloned managing systems of the lower hierarchical level form a managed object, and it is a managing system of the highest hierarchical level;

- some optimization criterion is introduced for this control system;

- for the resulting two-level hierarchical system, the principle of coordination is applied (Mesarović, Macko and Takahara, 1970; Mesarović, Macko and Takahara 1973; Dmitriev, 2020).

When implementing this conceptual approach, the main methodological problem is the criterion synthesis for the governing non-subject governing system. In many ways, these problems are similar to the problems discussed above to solve the problem.

Conceptual approach three is based on a typical vector criterion for optimizing managerial decisions about institutional and organizational separation. In this case, it is considered that a universal vector criterion for optimizing managerial decisions has been introduced, including taking into account goal-setting for all possible managerial situations:

$$
\vec{K}_{\text {un. }}(t) ; t \in\left(t_{\text {beg. }}, t_{\text {end. }}\right]
$$


Proposals for the composition of such universal optimization criteria are known (Dmitriev et al., 2013; Dmitriev and Novikov, 2018).

In this case, the initial criterion space for all management sub-periods becomes universal. Also, the dimensions and ordinal scales of all optimization criteria are identical. This optimization criterion is a thrice vector.

This vector is generated by:

- plurality of components of universal optimization criterion (there are M of them condition-ally);

- $\quad$ plurality of management subperiods (there are $\mathrm{N}$ of them);

- multiplicity of discrete-time instants for each management sub-period (their number in the general case can be arbitrary but must be no less than one. Otherwise, the management sub-period is from the managerial point of view with zero-length and therefore empty).

First, we will exclude the third factor that generates the triple vector. To ensure this, we will assume that:

- all optimization criteria are assessed at equally spaced discrete times (as a rule, they correspond to calendar periods such as quarters and years);

- all optimization criteria are evaluated and taken into account only for the endpoint of the sub-management period.

Thus, transformations of the now universal criterion space can only occur in the final sub-periods of management.

Accordingly, the optimization criterion takes the form of a matrix $\left(\left(\boldsymbol{K}_{d j}\right)\right) ; \boldsymbol{d} \in[\mathbf{1}, \boldsymbol{M}]$; $j \in[1, N]$.

To take into account the importance of the optimization criterion components, it is proposed to introduce a preference matrix $\left(\left(\alpha_{d j}\right)\right) ; d \in[1, M] ; j \in[1, N]$.

It can be appointed, for example, by the method of expert assessments (Sidel'nikov and Minaev, 2017), which does not at all mean rejection of direct one-time assignments of correlative importance on the part of the subject of management.

Most likely, in submatrices $\left(\left(\boldsymbol{\alpha}_{* j}\right)\right) ; \boldsymbol{j} \in[\boldsymbol{1}, \boldsymbol{N}]$ all elements, except one, will be zero. It is possible that in some situations it would be expedient to normalize the matrix $\left(\left(\alpha_{d j}\right)\right)$, for example, to one. Then, the final optimization criterion $\boldsymbol{K}_{\text {gl. }}\left(\boldsymbol{t}_{\text {end. }}\right)$ takes the following form:

$$
\boldsymbol{K}_{\text {gl. }}\left(\boldsymbol{t}_{\text {end. }}\right)=\sum_{j=1}^{N} \sum_{d=1}^{M} \boldsymbol{K}_{d j} * \boldsymbol{\alpha}_{d j .}
$$


Naturally, this expression provides that the signature definiteness of the optimization criterion's components is correct so that the additive formula is not paradoxical.

\subsection{Experience in the Application of Development Results}

The development described above has been tested in the following management areas:

- while optimizing the supply of aircraft engines and expensive components from 1985 to 1992. Several periods were singled out, for some of which optimization was carried out to ensure minimization of aircraft downtime, and in others to optimize the balanced values of net profits for suppliers and operators of this aviation technical property. Thus, as state indexes of the managing object (the park of complex final and component articles, their manufacturers, operators, and repair facilities) used the volume of fleet work, the size of the downtime of the park, the number of costs of the operator and the revenues of suppliers and repairers' components (Koval'kov, Dmitriev, 1994; Dmitriev, 2002b). A multi-purpose simulation model of the state of the fleet of final and component products was used as a tool for predicting condition indexes (Koval'kov, Dmitriev, 1994; Dmitriev, 2002b);

- when justifying systemic projects for the corporatization of several high-tech enterprises in 1996-2018, some of which were in a poor financial and economic condition. Thus, as state indexes of the managed object (a group of enterprises) used such indexes as net profit, outstanding accounts payable, tax deductions, etc. (Bodrunov, Dmitriev and Koval'kov, 2003; Dmitriev and Novikov 2018). A multi-purpose analytical model of a group of enterprises' financial and economic potential was used as a tool for predicting state indexes (Bodrunov, Dmitriev an Koval'kov, 2003; Dmitriev et al., 2013). In terms of content, it was the author's equivalent of such products as Project Expert $^{\mathrm{TM}}$ and Microsoft Project ${ }^{\mathrm{TM}}$;

- during the implementation of several dissertation projects of postgraduates and doctoral students in the field of management concerning enterprises and holding groups, carried out under the scientific supervision or overseeing of the author in the period 1996-2020 (more than 30 successful projects in total). The managed object, the composition of state indexes, and tools were similar to the previous area.

- There are reasons to recognize the testing experience as positive.

\section{Conclusion}

Based on the obtained results, we may formulate the following statements, conclusions and recommendations:

- in modern conditions, the problem of dimensional criterial dynamics inevitably arises, including in the economic field, which is caused, among other things, by sporadic crises. This dynamic is characteristic of institutional and organizational segregations at the macro, meso and 
micro levels;

- degree of theoretical elaboration of this problem area is extremely low, and applied experience is largely counterproductive. Accordingly, the use of the backlog is practically excluded;

- dimensional criterial dynamics generates an atypical vector optimization problem that cannot be solved within the framework of classical conceptual approaches;

- $\quad$ solution of this conceptual problem can be significantly approximated by introducing a number of conceptual innovations related to the use of the start-stop approach, emulation of the arbitration hierarchical system and universalization of the criterial space with its subsequent scalarization based on a method similar to the weighted utility method;

- practical experience of using the development is positive;

- this line of research is relevant and should be developed.

\section{References:}

Badalova, A.G., Minaev, E.S. 2016. Strategic risk management of enterprises of the aviation industry. Moscow: Moscow Aviation Institute.

Bazadze, N.G. 2002. Systematic methodology of organizational design of the management potential of high-tech production (on the example of Moscow and the Moscow region). Moscow: Moscow Aviation Institute.

Bennet, A., Bennet, D. 2004. Organizational Survival in the New World: Intelligent Complex Adaptive System. Amsterdam: Butterworth-Heinemann.

Bloshenko, A.A. 2009. The technology of integral assessment of the stability of the financial and economic state of an enterprise in Russian industry. Moscow: Moscow Aviation Institute.

Bodrunov, S.D., Dmitriev, O.N., Koval'kov Ju, A. 2003. Structural estimating of consequences of management decisions realization concerning enterprise Moscow: Gnome and D.

Cherner, N.V. 2019. Structuring the methodology of intracorporate price management of a Russian high-tech holding. Controlling, 1, 50-58.

Danilochkin, S.V. 2010. Methodological problems of dividend management of an industrial enterprise in Russia. Moscow: KnoRus.

Danilochkina, N.G. 2001. Controlling as a tool for enterprise management. Moscow: UNITI.

Demchenko, O.F. 2011. Methodology of mathematical modeling of organizational structures of the aviation-industrial complex of the Russian Federation. Moscow: KnoRus.

Dmitriev, O.N. 2002a. System analysis in management. Moscow: Gnome and D.

Dmitriev, O.N. 2002b. Intellectual information technology of feasibility report of marketing decisions - Moscow: Gnome and D.

Dmitriev, O.N. 2011. Conceptual problems of substantiating arbitration managerial decisions in economics. Proceedings of Moscow Aviation Institute, 49.

Dmitriev, O.N. 2020. Methodology Based on Coordinate Mode Principle for Interfacing of Management Systems in Case of Complex Organizational and Economic Separations. Amazonia Investiga, 9(28), 412-420.

Dmitriev, O.N., Novikov, S.V. 2018. Economic Assessment of Federal Scientific Programs. Russian Engineering Research, 38(4), 326-329.

Dmitriev, O.N., Novikov, S.V. 2019. Optimizing the Economic Information Transparency 
Level of High-Tech Enterprises in the Post-Industrial Globalized Economy. International Journal of Economics and Business Administration, 7(3), 25-56.

Dmitriev, O.N., Ekshembiev, S.K., Lyubaeva, Z.I., Koval'kov, J.A., Minaev, E.S. 2013. Corporate strategic management (fundamental and applied problems). Moscow: Kind Word.

Dubovik, M.V. 2011. Methodology for the formation of a strategy for managing counterparty competitiveness of the city's industrial complex at the meso-level. Moscow: Moscow Aviation Institute.

Ekshembiev, S.K. 2003. Methodology for organizing internal corporate management of financial and economic potential. Moscow: Moscow Aviation Institute.

Forrestor, D. 1971. Fundamentals of Enterprise Cybernetics. Moscow: Progress.

Gelfand, I.M. 1998. Lectures on linear algebra. Moscow: Dobrosvet.

Gorokhovik, V.V. 2012. Convex and nonsmooth vector optimization problems. Moscow: URSS Librocom.

Grigoriev, G.K. 2012. Adaptive management of networked dynamic systems with disturbances. Saint-Petersburg: Saint-Petersburg State University.

Ivanov, Y.V. 2003. Methodology of strategic management of institutional development of an industrial enterprise (on the example of the aluminum industry in Russia). Moscow: Moscow Aviation Institute.

Kleiner, I. 2007. History of Linear Algebra. A History of Abstract Algebra. Boston: Birkhäuser.

Koval'kov, J.A., Dmitriev, O.N. 1994. Effective Marketing Technologies - Moscow: Mashinostroenie [Machine Building].

Lapenkov, V.I. 2001. Methodology for managing the current liquidity of a manufacturing enterprise. Moscow Aviation Institute.

Lasdon, L.S. 1975. Optimizing for large systems. Moscow: Science.

Lasdon, L.S. 2002. Optimization Theory for Large Systems. New-York: Dover Publications.

Mesarović, M.D., Macko, D., Takahara, Y. 1970. Theory of Hierarchical Multilevel Systems. New York: Academic Press.

Mesarovich, M.D., Mako, D., Takahara, I. 1973. The theory of hierarchical multilevel systems. Moscow: Mir [World/Peace].

Nogin, V.D. 2005. Decision making in a multi-criteria environment: a quantitative approach. Moscow: FIZMATLIT [Physical and mathematical literature].

Nogin, V.D. 2016. Restricting the Pareto set: an axiomatic approach. Moscow: FIZMATLIT [Physical and mathematical literature].

Plaksin, M.A. 2007. Testing and debugging programs: for professionals, future and present. Moscow: Binom [Binomial].

Pyrkin, A.A. 2015. Adaptive control under conditions of lag, incomplete information about parameters and system state variables. Saint-Petersburg: Saint-Petersburg National Research University of Information Technologies, Mechanics and Optics.

Ruban, A.I. 2018. Adaptive managing systems with identification. Moscow: INFRA-M.

Shiryaev, A.N. 2020. Probabilistic-statistical methods in decision theory. Moscow: Moscow Center for Continuous Mathematical Education.

Shoemaker, P.J. 1982. The Expected Utility Model: Its Variants, Purposes, Evidence and Limitations. Journal of Economic Literature, 529-563.

Sidel'nikov, Y.V., Minaev, E.S. 2017. Expert scenario forecasting technology. Moscow: Moscow Aviation Institute.

Simakhin, V.A. 2019. Adaptive grades. Kurgan: Publishing house of the Kurgan State University. 
Solvit, S. 2012. Dimensions of War: Understanding War as a Complex Adaptive System. Paris: L'Harmattan.

Sorokin, O.D. 2019. Multidimensional ranking of objects. Novosibirsk: Academizdat.

Stadler, W. 1988. Multicriteria Optimization in Engineering and in the Sciences. New York: Plenum Press.

Tilahun, S.L., Ngnotchouye, J.M.T. 2018. Optimization Techniques for Problem Solving in Uncertainty. Hershey: IGI Global.

Vartanyan, A.A. 2008. Methodology of command-coalition management of the enterprise. Moscow: MAI-Print.

Wiener, N. 1983. Cybernetics. Moscow: Nauka [Science].

Yu-Chi, H., Qian-Chuan, Z., Qing-Shan, J. 2007. Ordinal Optimization: Soft Optimization for Hard Problems. New York: Springer.

Zeller, A. 2006. Why Programs Fail: a Guide to Systematic Debugging. Boston: Elsevier.

Zeller, A. 2011. Why Programs Don't Work: A Guide to System Debugging. Moscow: Eksmo.

Zolotova, V.A. 2017. Management problems and tasks of forming a program of anti-crisis management innovation in a high-tech enterprise of Russian industry. Moscow: KnoRus. 